\title{
MAIN FEATURES OF THE SAMARA-ULYANOVSK VOLGA REGION FLORA ADVENTIVE FRACTION FAMILY SPECTRUM
}

(C) 2018

Ivanova Anastasiya Viktorovna, candidate of biological sciences, researcher of Phytodiversity Problems Laboratory

Kostina Natalia Viktorovna, doctor of biological sciences, head of Ecosystems Modeling and Management Laboratory Institute of Ecology of the Volga River Basin of Russian Academy of Sciences (Togliatti, Samara Region, Russian Federation)

Lysenko Tatyana Mikhaylovna, doctor of biological sciences, leading researcher of General Geobotany Laboratory; leading researcher of Phytodiversity Problems Laboratory Komarov Botanical Institute of Russian Academy of Sciences (Saint Petersburg, Russian Federation); Institute of Ecology of the Volga River Basin of Russian Academy of Sciences (Togliatti, Samara Region, Russian Federation)

\begin{abstract}
The study of the adventive fraction of flora is a separate area of floristic research. General patterns of adventive species introduction consequences as well as their distribution throughout the territory are studied. Often, when studying the adventive fraction, the family spectrum is analyzed. In the paper we consider the adventive fraction of the flora on the territory of Samara-Ulyanovsk Volga Region, which is located within two natural zones: forest-steppe and steppe, four physical-geographical provinces and 15 districts. Each physical-geographical unit is characterized by its peculiarities of relief, geological structure, soils, vegetation and local climatic conditions. In the family spectrum of the adventive faction of Samara-Ulyanovsk Volga Region, it is possible to single out families that play a leading role in the formation of its composition. Based on the data on the adventive fractions of the floras of the physiographic regions and areas identified in the study area, it can be noted that the first four places in the spectrum are occupied by the following families Asteraceae, Poaceae, Brassicaceae and Chenopodiaceae. The list of these four leading families of the adventive fraction of the flora remains unchanged, but their order may be different. Probably, the differences in the natural conditions of the studied territories are reflected precisely in the order of the location of the leading families, since their composition does not change. The change in the composition of the leading four of the family spectrum can be observed on the scales of large areas: comparing the spectra of the adventive fractions of Ivanovo, Tver, Astrakhan Region, and other administrative divisions. Flora of various physical and geographical subdivisions of Samara-Ulyanovsk Volga Region, despite belonging to different natural zones, have similar family spectra of adventive fractions. They differ only in the presence of one or two families. For example, among the leading adventive families Rosaceae, Onagraceae and Rubiaceae were not in all cases.

Keywords: adventive fraction of flora; family spectrum of flora; leading families; Samara-Ulyanovsk Region; physico-geographical subdivisions.
\end{abstract}

\section{К ИТОГАМ ОЦЕНКИ КОЛИЧЕСТВЕННЫХ ПОКАЗАТЕЛЕЙ ЛИСТЬЕВ НЕКОТОРЫХ СОРТОВ И ГИБРИДОВ ПЛОДОВЫХ И ЯГОДНЫХ РОЗОЦВЕТНЫХ}

(C) 2018

Кавеленова Людмила Михайловна, доктор биологических наук, профессор, заведующий кафедрой экологии, ботаники и охраны природы

Петрова Анна Борисовна, аспирант кафедры экологии, ботаники и охраны природы Савицкая Кристина Андреевна, аспирант кафедры экологии, ботаники и охраны природы Янков Николай Викторович, биолог Ботанического сада

Самарский национальный исследовательский университет имени академика С.П. Королёва (2. Самара, Российская Федеращия)

Антипенко Мария Ивановна, кандидат сельскохозяйственных наук, ведущий научный сотрудник Деменина Любовь Георгиевна, ведущий научный сотрудник, заместитель директора по научной работе Кузнецов Анатолий Александрович, кандидат сельскохозяйственных наук, ведущий научный сотрудник Научно-исследовательский институт садоводства и лекарственных растений «Жигулёвские садыл» (2. Самара, Российская Федерация)

Аннотащия. Листья высших растений обнаруживают широкий спектр структурных и эколого-функциональных различий, выраженных для таксонов различного ранга, представителей экологических групп, а также связанных с адаптацией к комплексу биотопических условий. Среди количественных показателей, которые определяют при исследовании образцов листовой фитомассы, имеются выявляемые прямым измерением и расчетные. Вторая группа показателей включает в том числе массу единицы площади листовой пластинки (LMA). В природе у растений разных жизненных форм данный показатель обнаруживает различия в пределах двух порядков (от минимума у пресноводных гидрофитов до максимума у обитателей пустынь). Функциональные группы растений характеризуются неодинаковым уровнем пластичности LMA в градиенте из- 
Кавеленова Л.М., Петрова А.Б., Савицкая К.А., Янков Н.В., Антипенко М.И. и др. 03.02.00 - общая биология К итогам оценки количественных показателей листьев некоторых сортов и гибридов..

менений абиотических условий (света, температуры, увлажнения, эдафического режима). Оценка характеристик листового аппарата поверхности широко востребована в различных направлениях (экология растений, лесоводство, охрана окружающей среды, изучение сортов и пр.). В данном сообщении представлены обобщенные данные, относящиеся к итогам изучения структуры листьев для сортов и гибридов некоторых плодово-ягодных розоцветных (25 сортов груши, 15 - яблони, 13 - земляники садовой, 7 - клоновых подвоев для косточковых культур), для которых специалистами НИИ «Жигулевские сады» проводится сортоизучение. Для объединенных блоков данных по каждой группе объектов, с использованием пакета Ехсеl, нами выполнена процедура ранжирования ряда и построены гистограммы распределения. От частот мы перешли к процентному выражению доли переменных, соответствующих различному уровню LMA. Анализ распределения обобщенных данных по показателю массы единицы площади показал перспективность для сравнения групп объектов различной систематической (сортовой) принадлежности и выявления трендов различий между ними.

Ключевые слова: листья высших растений; количественные показатели; масса единицы площади листовой пластинки (LMA); плодово-ягодные розоцветные; сорта и гибриды; груша; яблоня; земляника садовая; клоновые подвои для косточковых культур; объединенные блоки данных; анализ распределения; ранжирование рядов; графики распределения; сравнения групп объектов.

Листья высших растений, при заметной выраженности единого плана тканевого строения, обнаруживают широкий спектр морфо-анатомических и эколого-функциональных различий, отражающих особенности, выраженные на уровне таксонов различного ранга, представителей экологических групп, а также являющиеся результатом адаптации к комплексу биотопических условий [1-5]. По целому ряду причин именно листья наиболее часто становятся объектом экофизиологических исследований, так как, при высокой функциональной активности, непосредственно связанной с уровнем продуктивности растений, листовая масса представляет доступный «расходный материал», неоднократное умеренное изъятие которого в течение вегетации не наносит заметного ущерба жизнедеятельности растений. Отбор проб листьев и их последующее изучение, как показывает анализ опыта отечественных и зарубежных исследователей и результаты нашей работы, целесообразно проводить в виде поэтапной реализации определенного алгоритма $[1 ; 3 ; 6-9]$, который может включать большее или меньшее число звеньев в зависимости от инструментальных возможностей и целей проводимого исследования.

Среди количественных показателей, которые определяются при исследовании образцов листовой фитомассы, существуют определяемые непосредственным измерением/исследованием и расчетные. В частности, к первой группе показателей F. Bussotti, M. Polliastrini [7] относят площадь листа, его свежую и сухую массу, массу при полном водонасыщении, толщину листа, толщину столбчатого и губчатого мезофилла, длину и ширину листовой пластинки, наибольшую ширину для левой и правой половин листовой пластинник, длину черешка, плотность устьиц, покрытие листовой пластинки трихомами. Вторая группа показателей включает полную и относительную (актуальную) водонасыщенность, массу единицы площади листовой пластинки (LMA), обратный по отношению к нему показатель удельной листовой поверхности (SLA), соотношение между столбчатым и губчатым мезофиллом (Pal/Spo), coдержание сухого вещества и показатель флуктуирующей асимметрии листовой пластинки (FA) [7].

Соотношение между сухой массой и площадью листовой пластинки (масса единицы площади, LMA) может рассматриваться как показатель, характеризующий на уровне органа эффективность улавлива- ния световой энергии, он является ключевым показателем ростовых процессов и индикатором жизненных стратегий растений. В природе у растений различных жизненных форм данный показатель обнаруживает различия в пределах двух порядков (от минимума у пресноводных гидрофитов до максимума у обитателей пустынь) [10]. Частично эти различия соотносятся с принадлежностью к определенным функциональным группам, в частности, вечнозеленые растения имеют наиболее высокие значения LMA, по сравнению с листопадными растениями они характеризуются большей толщиной листовых пластинок. Функциональные группы растений характеризуются неодинаковым уровнем пластичности LMA в градиенте изменений абиотических условий (света, температуры, увлажнения, эдафического режима $[1 ; 3-5 ; 8$; 10-12].

Особенности структуры листа, на разных уровнях определяющие итоговые значения LMA, были представлены Villar с соавт. [13] в схематическом виде (рис. 1).

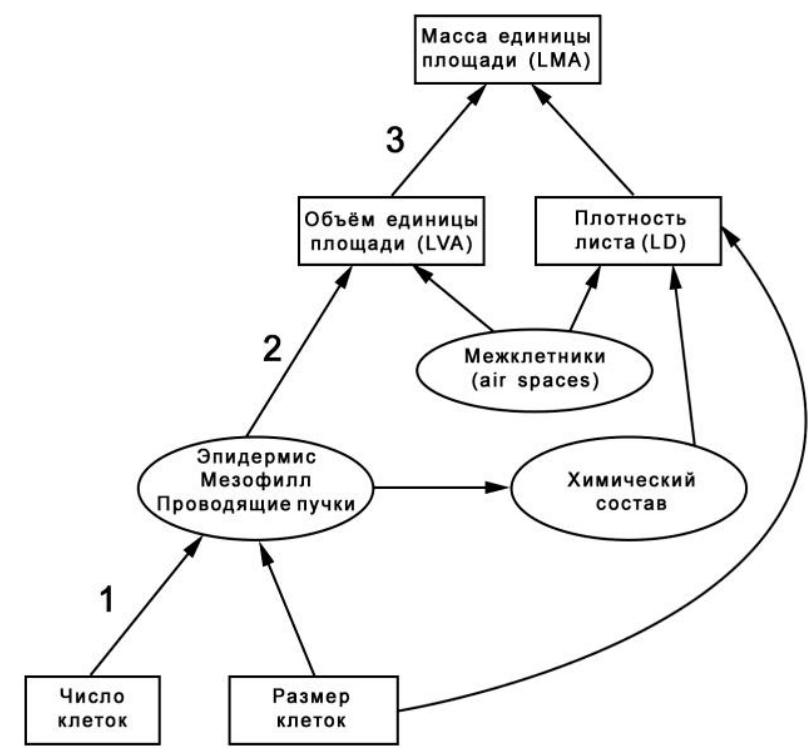

Рисунок 1 - Принципиальная схема анатомических особенностей на трех уровнях интеграции, показывающая причины различий показателя LMA (из [13], с незначительными изменениями). 1- клетка, 2-орган, 3-ткань

Указанные на схеме особенности тканевого строения частично соотносятся с приведенным выше перечнем непосредственно измеряемых показателей 
листа, рекомендуемым [6; 7]. Следует отметить, что проведение скрининга анатомической структуры листа все же представляет собой, при предложенном нами варианте изучения листовой массы, дополнительное (параллельное) направление работы. Оценка характеристик листовой поверхности широко востребована в различных направлениях (экология растений, лесоводство, охрана окружающей среды, изучение адаптивного потенциала сортов и пр.). В данном сообщении мы хотели бы представить некоторые обобщенные данные, относящиеся к итогам изучения структуры листьев для сортов и гибридов некоторых плодово-ягодных розоцветных (сорта груши, яблони, земляники садовой $[14 ; 15]$, клоновых подвоев для косточковых культур [16; 17]), для которых специалистами НИИ «Жигулевские сады» проводится сортоизучение.

\section{Методика работы}

Нами были проанализированы структурно-функциональные особенности листового аппарата 7 клоновых подвоев для косточковых культур, 25 сортов груши, 13 сортов земляники садовой, в 2017 г. начато изучение по сортам яблони, для них в настоящем сообщении рассматриваются первичные итоги скрининга.

Сбор показателей по каждой группе объектов проводился не менее 3 вегетационных периодов. Отбор проб листовой массы по различным группам объектов проводилась ежемесячно специалистами НИИ «Жигулевские сады»:

- в 2008-2013 гг. - для клоновых подвоев Весеннее Пламя, ВСЛ-2, ВЦ-13, Дружба, ЛЦ-52, Фортуна, Эврика;

- в 2012-2015 гг. - для сортов груши Александра, Болеро, Болеро-1, Воложка, Волшебница, Галиана, Герда, Даренка, Жигулинка, Журавлинка, Краса Жигулей, Кристина, Лакомка, Лебедушка, Маршал Жуков, Осенняя крупная, Ранняя, Румяная Кедрина, Самарская Жемчужина (Зимняя), Самарская красавица, Самарянка, Скромница, Средневолжская, Усолка, Чижовская;

- в 2012-2014 - для сортов земляники садовой Блестящая, Жанна, Звездочка, Зенга Зенгана, Избранница, Источник, Кама, Кармен, Лорд, Онега, Осенняя Ранняя, Пандора, Фестивальная;

- в 2017 г. было начато изучение листьев для сортов яблони. Для статьи мы используем данные, относящиеся к 15 сортам, по которым имеются данные за два вегетационных периода: осенние сорта - Азаровское, Буян, Волжанин, Жигулевское, Красноглинское, Куйбышевское, Кутузовец, Подарок Министру, Презент, Самара, Самарский сувенир, Синап Самарский, Скиф; Сокское розовое, Спартак, Утес.

Пробы листьев передавались в лаборатории кафедры экологии, ботаники и охраны природы, где по разработанной нами схеме [9] выполнялись скрининговая оценка ведущих экофизиологических параметров, включая показатели массы и водного режима листьев, а также расчет LMA - массы единицы площади листовых пластинок.

\section{Результаты исследований и их обсуждение}

Частные результаты, относящиеся к различным показателям листьев изучавшихся сортов и гибри- дов, были опубликованы нами ранее (например, [1823]). Однако результаты по отдельным годам наблюдений, как мы неоднократно обнаруживали, носят отпечаток своеобразия погодных условий конкретных вегетационных периодов [8; 9; 19; 23], тогда как обобщение данных за ряд лет позволяет выявить наличие изначально неявных зависимостей.

Подтвердим это, используя обобщенные данные по показателю массы единицы площади LMA для зрелых листьев различных групп объектов (усредненные показатели июльских образцов сортов за различные вегетационные периоды). Для объединенных блоков данных по каждой группе объектов, используя пакет Excel, мы выполнили процедуру ранжирования ряда и построили гистограммы распределения [24]. При различном числе сортов и лет наблюдений каждый ряд данных был составлен из неодинакового количества переменных (96 для сортов груши, 35 - для земляники, 42 - для клоновых подвоев, 30 - для яблони). Поэтому для сопоставления графиков распределения показателей мы перешли от частот к процентному выражению доли переменных, соответствующих различному уровню LMA (рис. 2).

Как известно, визуализированная графиком картина распределения может рассматриваться с учетом выраженности максимума распределения и второстепенных максимумов, симметричности, сходства с кривой нормального распределения [24]. Можно отметить, что среди изучавшихся культур распределение показателей у сортов земляники садовой выражается «самой симметричной» кривой с наиболее отчетливым максимумом (значение LMA около

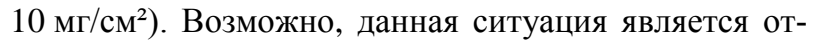
ражением экофизиологического сходства изученных растений, но мы не можем полностью исключить влияния сравнительной малочисленности изученной группы сортов.

Показатели клоновых подвоев, для которых период изучения был самым длительным, продемонстрировали меньшее по сравнению с другими объектами значение максимума (наиболее часто отмечав-

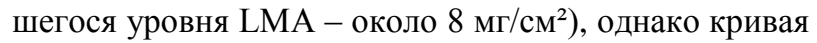
распределения показывает значительную долю переменных с уровнем значений - около $1 \mathrm{Mг} / \mathrm{cm}^{2}$. Это подтверждает внутреннюю неоднородность рассматриваемой группы, поскольку клоновые подвои представляют гибриды таксономически разного происхождения [16;17].

Для сортов груши, а также по предварительным данным - особенно для сортов яблони графики распределения по уровню LMA также указывают на неоднородность групп, что может быть связано с генотипическими различиями сортов, присутствием в группах сортов с разными сроками созревания плодов и пр. В целом предварительные данные по структуре листовых пластинок у сортов яблони демонстрируют более высокий уровень показателя LMA, чем у сортов груши, что является отражением большей степени ксероморфности листьев сортов яблони по сравнению с листьями сортов груш. Данный факт вполне совпадает с общеизвестной характеристикой груши как более влаголюбивой по сравнению с яблоней плодовой культуры. 


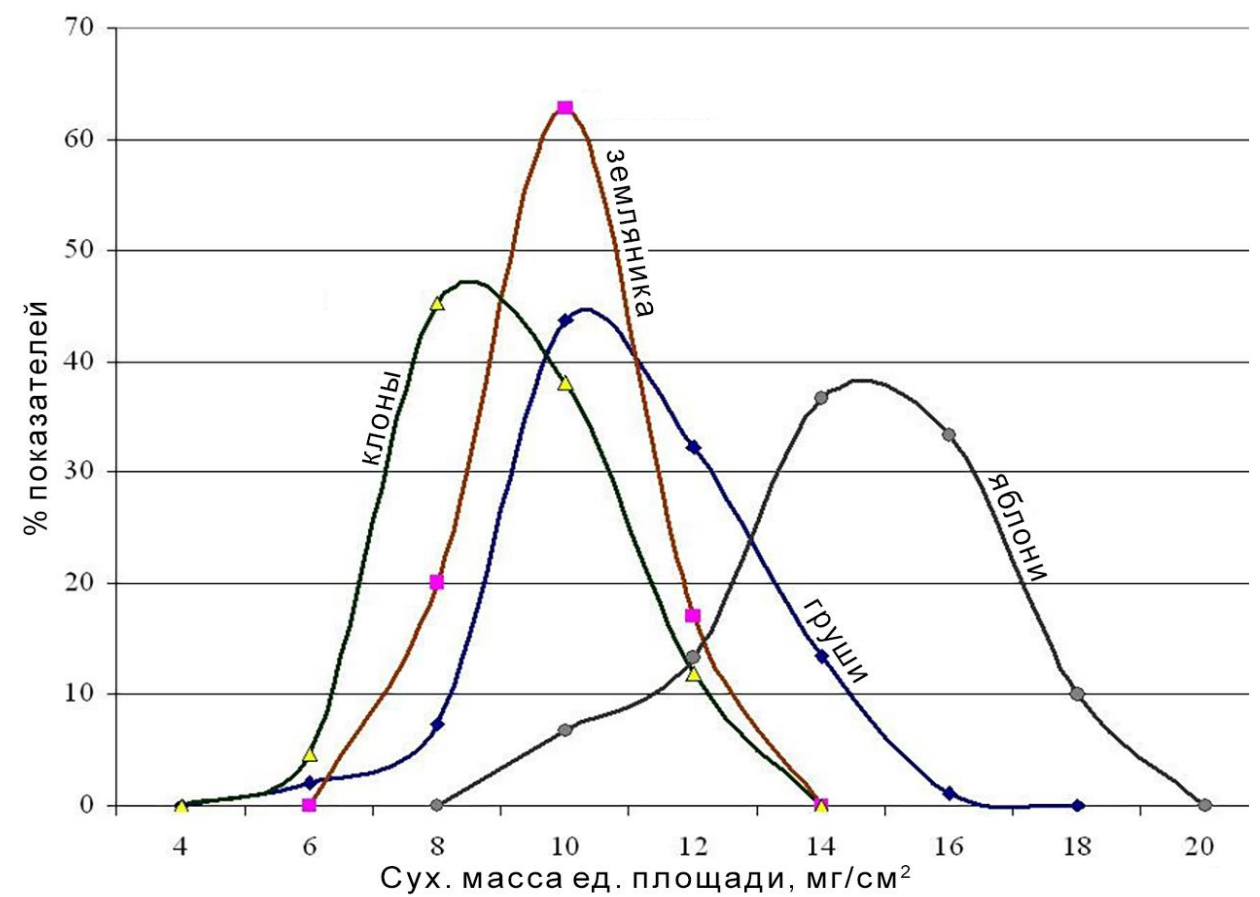

Рисунок 2 - Распределение сортов груши, земляники, яблони и клоновых подвоев для косточковых культур по показателю массы единицы площади - LMA. Примечание

Использованы показатели, соответствующие зрелым листовым пластинкам (июль)

Таким образом, анализ распределения обобщенных данных по показателю массы единицы площади может быть применен для сравнения групп объектов различной систематической (сортовой) принадлежности и выявления трендов различий между ними. В частности, по рассматриваемым группам сортов культивируемых розоцветных ряд рейтинга в соответствии с наиболее часто встречающимся уровнем показателя массы единицы площади листа (максимум кривых распределения) выглядит как: «клоновые подвои для косточковых» < «сорта земляники садовой, груши» < «сорта яблони». Сорта груши и по предварительной оценке - яблони характеризуются заметными различиями по показателю массы единицы площади зрелых листьев. Предварительные данные по структуре листовых пластинок у сортов яблони демонстрируют более высокий уровень показателя LMA по сравнению с изучавшимися сортами груши.

\section{Список литературы:}

1. Уткин А.И., Ермолова Л.С., Уткина И.А. Площадь поверхности лесных растений: сущность, параметры, использование. М.: Наука, 2008. 292 с.

2. Васильев Б.Р. Строение листа древесных растений различных климатических зон. Л.: Изд-во ЛГУ, 1988. 208 с.

3. Васфилов С.П. Анализ причин изменчивости отношений сухой массы листа к его площади у растений // Журнал общей биологии. 2011. Т. 72, № 6. C. $436-454$.

4. Garnier E., Laurent G. Leaf anatomy, specific mass and water content in congeneric annual and perennial grass species // New Phytologist. 1994. Vol. 128. P. 725-736.

5. Villar R., Merino A. Comparison of leaf construction cost in woody species with differing leaf life-spans in contrasting ecosystems // New Phytologist. 2001. Vol. 151. P. 213-226.
6. Cornelissen J.H., Lavorel S.B., Garnier E.B. A handbook of protocols for standardised and easy measurement of plant functional traits worldwide // Australian Journal of Botany. 2003. Vol. 51. P. 335-380.

7. Bussotti F., Polliastrini M. Evaluation of leaf features in forest trees: Methods, techniques, obtainable information and limits // Ecological Indicators. 2015. Vol. 52. P. 219-230.

8. Кавеленова Л.М., Розно С.А., Киреева Ю.В., Смирнов Ю.В. К структурно-функциональным особенностям листьев древесных растений в насаждениях лесостепи // Самарская Лука. Бюллетень. 2007. T. 16, № 3 (21). С. 568-574.

9. Кавеленова Л.М., Малыхина Е.В., Розно С.А., Смирнов Ю.В. К методологии экофизиологических исследований листьев древесных растений // Поволжский экологический журнал. 2008. № 3. С. 200-210.

10. Poorter H., Niinemets U., Poorter L., Wright I.J., Villar R. Causes and consequences of variation in leaf mass per area (LMA): a meta-analysis. Tansley review // New Phytologist. 2009. Vol. 182. P. 565-588.

11. Roderick M.L., Berry S.L., Saunders A.R., Noble I.R. On the relationship between the composition, morphology and function of leaves // Functional Ecology. 1999. Vol. 13. P. 696-710.

12. Niinemets U., Kull O., Tenhunen J.D. An analysis of light effects on foliar morphology, physiology, and light interception in temperate deciduous woody species of contrasting shade tolerance // Tree Physiology. 1998. Vol. 18. P. 681-696.

13. Villar R., Ruiz-Robleto J., Ubera J.L., Poorter H. Exploring variations in leaf mass per area (LMA) from leaf to cell: an anatomical analysis of 26 woody species // American Journal of Botany. 2013. Vol. 100 (10). P. 1969-1980.

14. Лучшие сорта плодовых, ягодных культур и винограда селекции государственного бюджетного учреждения Самарской области «Научно-исследова- 
тельский институт садоводства и лекарственных растений «Жигулевские сады». Самара: ООО Изд-во АсГард, 2013. 148 с.

15. Кузнецов А.А. Подбор и оценка исходного материала для селекции груши в условиях Среднего Поволжья: автореф. дис. ... канд. биол. наук, Кинель, 2011. $24 \mathrm{c}$.

16. Еремин Г.В., Проворченко А.В., Гавриш В.Ф. и др. Косточковые культуры. Выращивание на клоновых подвоях и собственных корнях. Ростов-наДону: Феникс, 2000. 256 с.

17. Еремин Г.В., Семенова Л.Г., Гасанова Т.А. Физиологические особенности формирования адаптивности, продуктивности и качества плодов у косточковых культур в Предгорной зоне Северо-Западного Кавказа. Майкоп: Адыг. респ. кн. изд-во, 2008. 210 с.

18. Малыхина Е.В., Кавеленова Л.М., Минин А.Н. К оценке экофизиологических особенностей клоновых подвоев для косточковых культур в лесостепи Среднего Поволжья // Известия Самарского научного центра РАН. 2009. Т. 11, № 1 (4). С. 711-714.

19. Кравцева А.С., Кавеленова Л.М. К оценке биоэкологических особенностей листьев клоновых подвоев в условиях экстремальной засухи // Проблемы садоводства в Среднем Поволжье. Самара, 2011. C. $158-162$.

20. Кавеленова Л.М., Кравцева А.П., Трубников А.М., Янков Н.В. К возможностям оценки функ- циональной активности листовых пластинок древесных растений // Известия Самарского научного центра Российской академии наук. 2013. Т. 15, № 3 (7). C. 2333-2336.

21. Брагина О.М., Власова Н.В., Кравцева А.П., Петрова А.Б., Помогайбин Е.А., Трубников А.М., Янков Н.В. Особенности химического состава фитомассы некоторых дикорастущих и культивируемых древесных растений: к оценке зольного компонента // Известия Самарского научного центра РАН. 2014. T. 16, № 1 (3). С. 724-727.

22. Кравцева А.П., Петрова А.Б., Савицкая К.С., Кавеленова Л.М., Кузнецов А.А., Антипенко М.И. Особенности сезонной динамики зольного компонента в листьях различных сортов груши и земляники // Вестник молодых ученых и специалистов Самарского государственного университета. 2014. № 2. C. 31-36.

23. Кавеленова Л.М., Савицкая К.А., Петрова А.Б., Кравцева А.П., Антипенко М.И., Кузнецов А.А. К индикационной значимости изменения показателей листьев в различные по благоприятности вегетационные периоды // Вестник молодых ученых и специалистов Самарского государственного университета. 2015. № 2 (7). С. 81-85.

24. Зайцев Г.Н. Математическая статистика в экспериментальной ботанике. М.: Наука, 1984. 424 с.

\section{RESULTS OF QUANTITATIVE PARAMETERS EVALUATION OF LEAVES OF SOME FRUIT AND BERRY ROSACEAE CULTIVARS AND HYBRIDS}

(C) 2018

Kavelenova Lyudmila Mikhailovna, doctor of biological sciences, professor, head of Ecology, Botany and Nature Protection Department

Petrova Anna Borisovna, postgraduate student of Ecology, Botany and Nature Protection Department

Savitskaya Kristina Andreevna, postgraduate student of Ecology, Botany and Nature Protection Department Yankov Nikolay Viktorovich, biologist of Botanical Garden Samara National Research University (Samara, Russian Federation)

Antipenko Maria Ivanovna, candidate of agricultural sciences, leading researcher Demenina Lyubov Georgievna, leading researcher, deputy director for science

Kuznetsov Anatoly Alexandrovich, candidate of agricultural sciences, leading researcher Research Institute of Horticulture and Medicinal Plants «Zhiguliovskye Sady» (Samara, Russian Federation)

Abstract. The leaves of higher plants reveal a wide range of structural and ecofunctional differences expressed for taxa of various ranks, for representatives of ecological groups, as well as associated with adaptation to a complex of biotopic conditions. Among the quantitative indicators determined in the study of leaf phytomass samples there are some detected by direct measurement and others detected by calculating. The second group of indicators includes, in particular, the leaf mass per area (LMA) parameter. In nature, this indicator reveals differences within two orders for plants of various life forms (from the minimum in freshwater hydrophytes to the maximum in desert inhabitants). Functional groups of plants are characterized by unequal level of LMA plasticity in the gradient of abiotic conditions (such as light, temperature, moisture, edaphic regime). Evaluation of leaf apparatus parameters is widely demanded in various actual directions (plant ecology, forestry, environmental protection, cultivars study, etc.). In this paper we present some generalized data related to the results of the study of the leaf structure for some fruit and berry Rosaceae cultivars and hybrids (25 varieties of pears, 15 - apple, 13 - garden strawberries, 7 - clone rootstocks for stone fruit crops), for which the Scientific Research Institute «Zhigulevskiye Sady» specialists carry out cultivars study. We performed a row ranking procedure and constructed distribution histograms for the integrated data blocks for each group of objects, using the Excel. We turned to the percentage of the proportion of variables corresponding to different levels of LMA. The distribution analysis of generalized data on the LMA index showed perspectivity for comparing groups of objects of different systematic (varietal) accessories and for detection of dissimilarity trends between them.

Keywords: leaves of higher plants; quantitative parameters; leaf mass per area (LMA); fruit and berries; family Rosaceae; cultivars and hybrids; pear; apple; strawberry; clone rootstocks for stone fruit crops; integrated data blocks; distribution analysis; ranking of rows; distribution graphs; comparison of objects groups. 